\title{
Chromium speciation in leather samples: an experiment using digital images, mobile phones and environmental concepts
}

\author{
Vinícius Costa ${ }^{1}$, Ariane Neiva ${ }^{1}$, Edenir Pereira-Filho ${ }^{1+(10}$ \\ ${ }^{1}$ Federal University of São Carlos - UFSCar, São Paulo, Brazil \\ + Corresponding author: Edenir Pereira-Filho, e-mail address: erpf@ufscar.br
}

\section{ARTICLE INFO}

Article history:

Received: October 03, 2018

Accepted: December 11, 2018

Published: January 28, 2019
Keywords:

1. PhotoMetrix

2. digital image

3. mobile phone

4. leather and $\mathrm{Cr}(\mathrm{VI})$

ABSTRACT: This study proposes a new and simple method for $\mathrm{Cr}$ speciation and $\mathrm{Cr}(\mathrm{VI})$ determination in leather samples using digital images. The experiments were performed using a mobile phone and a free app called PhotoMetrix that was used to obtain and process data. The results obtained from PhotoMetrix were compared to reference methods using UV-Vis. A statistical evaluation between both proposed and the reference methods using two-sample t-test did not show a significant difference at a 95\% confidence level. Bovine leather samples (4 samples) tanned with $\mathrm{Cr}$ salts and ovine leather samples (3 samples) tanned with

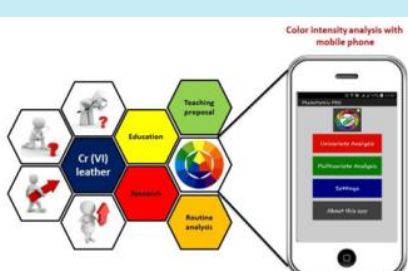
The use of the smartphone is an excellent tool for the introduction of quantitative analysis vegetable tannin were analyzed. The proposed method presented limits of detection (LOD) and quantification (LOQ) of $0.6 \mathrm{and} 2 \mathrm{mg} / \mathrm{kg}$, respectively. In addition, the proposed method using PhotoMetrix and digital images can provide undergraduate students an opportunity to learn topics such as quantitative analyses, environmental chemistry, speciation chemistry, image processing and treatment of statistical data. The results demonstrated that the proposed method can be applied to routine analyses and in experimental analytical chemistry courses.

\section{Introduction}

Quantitative instrumental methods based on atomic spectrometry are commonly used to determine $\mathrm{Cr}(\mathrm{VI})$, however these techniques are expensive and are not available in several universities, especially those located in developing countries $^{1-3}$. An image for analysis can be obtained from a mobile phone, scanner or webcam that are versatile instruments and easy to operate. Undergraduate students enjoy interactive and attractive classes, and the use of these tools can be an interesting approach for the experimental part of a laboratory exercise. In recent years, several research groups have used mobile phones and scanners in laboratory classes for determination of metals in several samples ${ }^{4-6}$.

Digital images can provide a large amount of data from the extraction of picture elements called pixels, where each pixel is characterized by different channels. The color system most commonly used for color images is red (R), green (G) and blue (B). Although RGB is the most frequently used color model, there are others that can be generated from it, such as hue, saturation and value (HSV); hue, saturation and lightness (HSL); cyan, magenta, yellow, key or black (CMYK) color space; and hue, saturation and intensity (HSI). In these models, hue $(\mathrm{H})$ is associated with how most people recognize a color, for example, the differentiation between red and yellow. Saturation (S) is the amount of the color that is present in an image, for example, the differentiation between red and pink. Value (V), lightness (L), or intensity (I) are related to the amount of light, such as the distinction between dark and light red or between dark and light gray. Value is defined as the highest amount among R, G 
or B, intensity as the average of R, G or B colors, and lightness is defined as the average of the maximum and minimum amounts of $\mathrm{R}, \mathrm{G}$ or $\mathrm{B}^{7}$.

In 2016, a new free app called PhotoMetrix for image analysis was proposed by Grasel and coauthors $^{8}$. The authors used PhotoMetrix for the identification of tannins according the source type (chestnut, valonea, quebracho, black wattle, tara and myrobalan). PhotoMetrix was used in module multivariate analysis, and images were analyzed using RGB histograms and HSI channels. Principal component analysis (PCA) was employed to verify separation among sample groups. In other study using PhotoMetrix, Helffer and collaborators ${ }^{9}$ proposed a simple method for determination of $\mathrm{Fe}$ in supplements. The determination of $\mathrm{Fe}$ in these samples was performed in univariate mode and differentiation among them was performed in multivariate mode using PCA.

In this sense, the present study proposed a new method for $\mathrm{Cr}$ speciation and $\mathrm{Cr}(\mathrm{VI})$ determination in leather samples by digital images using the PhotoMetrix app and a mobile phone to obtain, prepare, handle the data, and perform the calculations. This method is simple and obeys the principles of green chemistry as it requires minimum number and quantity of reagents and can be performed in a fast, non-destructive and inexpensive manner. In addition, the method can be applied in laboratory classes and several chemical concepts can be addressed with students.

\section{Materials and methods}

\subsection{Experimental details}

The experiments related to image analysis, data processing and treatment were accomplished in an analytical chemistry laboratory course with 15 students. The students were divided into groups, and each one was responsible for part of the activities. Group 1 was responsible for standard solutions preparation, Group 2 was responsible for alkaline $\mathrm{Cr}(\mathrm{VI})$ extraction in leather samples and Group 3 was related to data acquisition, processing, and results compilation and organization. A total of 4 hours was needed to carry out the experiments. The results obtained by ICP OES (inductively coupled optical emission spectrometry) for total $\mathrm{Cr}$ determination were previously provided to the students.

\subsection{Instrumentation}

Digital images were obtained using the PhotoMetrix app version 1.0.5 using a cell phone. The PhotoMetrix application in the "Univariate Analysis" mode captures images using the camera of the mobile device. The images can be analyzed using two modes, vector RGB and multi-channel. In vector RGB mode, $R, G, B$ average values are used to calculate the Euclidean norm of the values. In multi-channel mode, each color channels (R, G, $\mathrm{B}, \mathrm{H}, \mathrm{S}, \mathrm{V}, \mathrm{L}, \mathrm{I}$ ) is used individually. PhotoMetrix also allows the use of different spot sizes $(32 \times 32$; $64 \times 64 ; 96 \times 96$ pixels) to obtain images. The mobile phone was mounted on an apparatus made from a wooden box $(16.5 \times 29.5$ and $9.5 \mathrm{~cm}$ in height), with a holder to attach the phone (similar to those found in cars to mount a mobile phone) and a hole for the phone camera, as shown in Figure S1 (see Supplementary Material).

Reference concentrations of total $\mathrm{Cr}$ were obtained with an ICP OES (iCAP 6000, Thermo Scientific, Waltham, MA, USA), after acid extraction of the samples $(n=3)$. This instrument allows collection of sequential emission signals, using both axial and radial viewings. Argon (99.996\%, White Martins-Praxair, Sertãozinho, SP, Brazil) was used as a plasma gas for ICP OES and additional instrumental parameters are shown in Table S1 (see Supplementary Material). Reference concentrations of $\mathrm{Cr}(\mathrm{VI})$ were obtained using a spectrophotometer (Thermo Fisher, Shanghai, China), in $540 \mathrm{~nm}$ wavelength and a quartz cuvette with $1 \mathrm{~cm}$ of optical path.

\subsection{Reagents, solutions and samples}

All solutions were prepared by students. Ultrapure water (18.2 $\mathrm{M} \Omega \mathrm{cm}$ resistivity) produced by a Milli-Q Plus Total Water System (Millipore Corp., Bedford, MA, USA) was used to prepare all the aqueous solutions. Nitric acid $\left(\mathrm{HNO}_{3}\right)$ was previously purified using a sub-boiling distillation system, Distillacid BSB-939-IR (Berghof, Eningen, Germany), and hydrogen peroxide, $\left(\mathrm{H}_{2} \mathrm{O}_{2}\right) 30 \%$ w/w (Synth, Diadema, Brazil), was used for the digestion of samples to determine total $\mathrm{Cr}$. The analytical curve for determination of total $\mathrm{Cr}$ was prepared in the range 0.005 to $60 \mathrm{mg} \mathrm{L}^{-1}$. All glassware and polypropylene flasks were washed with soap, soaked in $10 \% \mathrm{v} / \mathrm{v} \mathrm{HNO}_{3}$ for 24 $\mathrm{h}$, and rinsed with deionized water prior to use. 
A standard stock solution containing $1000 \mathrm{mg}$ $\mathrm{L}^{-1}$ of $\mathrm{Cr}(\mathrm{VI})$ was prepared by weighing an adequate mass of a primary standard, potassium dichromate $\left(\mathrm{K}_{2} \mathrm{Cr}_{2} \mathrm{O}_{7}\right)$ (Synth, São Paulo, Brazil), previously dried at $160{ }^{\circ} \mathrm{C}$ for $2 \mathrm{~h}$. The reagents sodium hydroxide $(\mathrm{NaOH})$, sulfuric acid $\left(\mathrm{H}_{2} \mathrm{SO}_{4}\right)$, 1,5-diphenylcarbazide (DPC) and acetone were purchased from Merck (Darmstadt, Germany).

The alkaline extraction of $\mathrm{Cr}(\mathrm{VI})$ was performed using a $0.1 \mathrm{~mol} \mathrm{~L}^{-1} \mathrm{NaOH}$ solution. A $5.0 \mathrm{~mol} \mathrm{~L}^{-1} \mathrm{H}_{2} \mathrm{SO}_{4}$ solution was prepared to adjust the $\mathrm{pH}$ of the extracts. In addition, a DPC solution was prepared daily by dissolving $0.2 \mathrm{~g}$ of the reagent in $10 \mathrm{~mL}$ of acetone and diluting to $100 \mathrm{~mL}$ with deionized water. The DPC solution was then stored in an amber flask to avoid degradation by the environmental light. The calibration curve to determine $\mathrm{Cr}(\mathrm{VI})$ concentration by digital images was prepared in the range from 0.05 to $0.75 \mathrm{mg} \mathrm{L}^{-}$ ${ }^{1}$ and a $\mathrm{Cr}$ (III) solution (Qhemis, Jundiaí, SP, Brazil) containing $50 \mathrm{mg} \mathrm{L}^{-1}$ was prepared and used in the addition and recovery tests. Seven leather samples were acquired from Embrapa Pecuária Sudeste (São Carlos, SP, Brazil) and analyzed in this study. The leathers were tanned with $\mathrm{Cr}$ salts (bovine samples: 1 to 4) and vegetable tannin (ovine samples: 5 to 7). Additional details about the process of leather tanned using $\mathrm{Cr}$ salts are available in publication of Dixit et al. ${ }^{10}$.

\subsection{Sample preparation to determine total $\mathrm{Cr}$ and $\mathrm{Cr}(\mathrm{VI})$}

To determine total $\mathrm{Cr}$, a reference extraction procedure proposed by Neiva and Pereira-Filho ${ }^{11}$ was used. The extraction procedure for determination of $\mathrm{Cr}(\mathrm{VI})$ using the reference method by UV-Vis and proposed procedure using digital images is described below. The general procedure is represented in Figure 1.
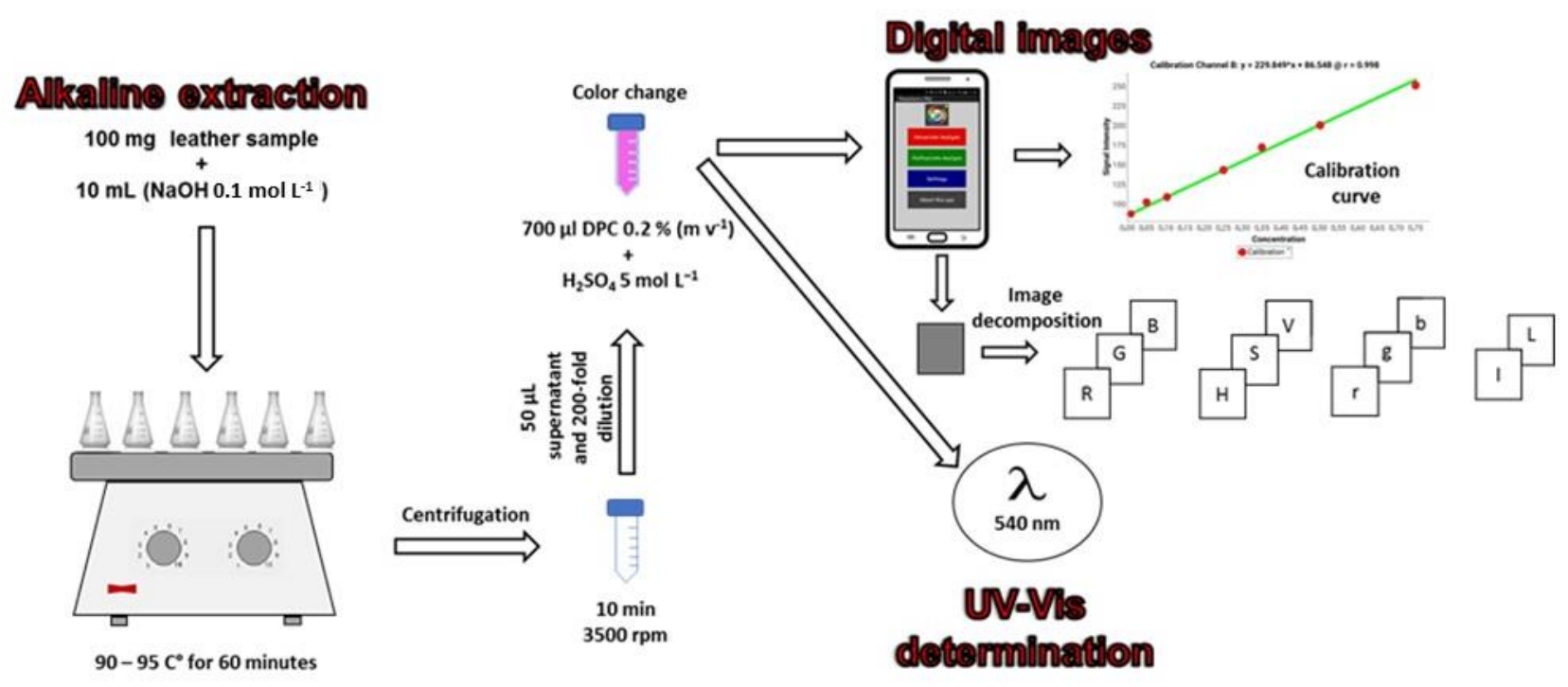

Figure 1. Pictorial for procedure of extraction to $\mathrm{Cr}(\mathrm{VI})$, for determination by digital images acquisition and UV-Vis determination.

For $\mathrm{Cr}(\mathrm{VI})$ extraction, $100 \mathrm{mg}$ of leather samples were weighed in Erlenmeyer flasks, and $10 \mathrm{~mL}$ of $0.1 \mathrm{~mol} \mathrm{~L}^{-1} \mathrm{NaOH}$ solution were added. This solution was placed on a hot plate (208-2 D, Nova Ética, São Paulo, Brazil) for 60 min at 90$95^{\circ} \mathrm{C}$ with sporadic shaking. When it reached room temperature, the solution was transferred to plastic tubes and centrifuged ( $3500 \mathrm{rpm}$ for $3 \mathrm{~min}$ ).
A $50 \mu \mathrm{L}$ aliquot of the supernatant solution was collected and diluted 200 -fold. Later, $700 \mu \mathrm{L}$ of $0.2 \%(\mathrm{w} / \mathrm{v}) \mathrm{DPC}$ solution was added and, after this, the $\mathrm{pH}$ was adjusted to 1.0 with $5 \mathrm{~mol} \mathrm{~L}^{-1} \mathrm{H}_{2} \mathrm{SO}_{4}$ solution until the solution changed to a pink color ${ }^{12}$. To verify the performance of the proposed method, addition and recovery experiments were employed. In the recovery tests, a known concentration of 
$\mathrm{Cr}(\mathrm{III})$ and $\mathrm{Cr}(\mathrm{VI})$ was added to the samples before the alkaline extraction and the determinations were carried by $\mathrm{UV}-\mathrm{V}$ is and digital images.

\subsection{Hazard}

The students were advised to use safety goggles, gloves and lab vests during the experimental procedure and to take extreme care in acid and solutions preparation and manipulations. The $\mathrm{Cr}(\mathrm{VI})$ extraction was performed in a fume hood. In addition, all the $\mathrm{Cr}(\mathrm{VI})$ waste were separated for proper treatment and disposal.

\section{Results and discussion}

\subsection{Optimization of the PhotoMetrix parameters}

Initially, some experiments were performed to verify the influence of spot size (number of pixels) in the recording of the digital images. To select the best spot size, the linear determination coefficient $\left(\mathrm{R}^{2}\right)$ of the analytical curves was used. The spot size that presented the best $R^{2}$ value of the analytical curves was $64 \times 64$ pixels. To select the best color parameter (vector $R G B$ and multichannel), we used a standard solution of $\mathrm{Cr}(\mathrm{VI})$ at $0.35 \mathrm{mg} \mathrm{L} \mathrm{L}^{-1}$, and from the analytical curve obtained, the standard concentration was predicted. The parameters obtained for vector $R G B$ and multichannel histograms are presented in Table 1.

Table 1. Analytical parameters obtained for the different color channels.

\begin{tabular}{cccccc}
\hline Histograms & Channel & Linear equation & $\mathbf{R}^{\mathbf{2}}$ & \% recovery \\
\hline Vector RGB & RGB & $\mathrm{y}=212.122 \mathrm{x}+12.361$ & 0.981 & 60 \\
\hline & $\mathrm{B}$ (Blue) & $\mathrm{y}=203.404 \mathrm{x}+106.733$ & 0.993 & 109 \\
\cline { 2 - 5 } & $\mathrm{V}$ (Value) & $\mathrm{y}=0.893 \mathrm{x}+0.343$ & 0.991 & 120 \\
\cline { 2 - 5 } & L (Lightness) & $\mathrm{y}=0.390 \mathrm{x}+0.342$ & 0.985 & 122 \\
\cline { 2 - 5 } & $\mathrm{I}$ (Intensity) & $\mathrm{y}=0.246 \mathrm{x}+0.343$ & 0.963 & 122 \\
\cline { 2 - 5 } Multi-channel & $\mathrm{S}$ (Saturation) & $\mathrm{y}=1.000 \mathrm{x}+0.104$ & 0.932 & 115 \\
\cline { 2 - 5 } & $\mathrm{H}$ (Hue) & $\mathrm{y}=87.406 \mathrm{x}+191.671$ & 0.546 & 38 \\
\cline { 2 - 5 } & $\mathrm{G}$ (Green) & $\mathrm{y}=-14.204 \mathrm{x}+88.399$ & -0.392 & -213 \\
\cline { 2 - 5 } & $\mathrm{R}$ (Red) & $\mathrm{Y}=-27.707 \mathrm{x}+87.105$ & -0.806 & -235 \\
\hline
\end{tabular}

The color channel B (blue) showed the best trueness (109\%) and so was selected for the further experiments. In addition, channel B presented an $\mathrm{R}^{2}$ of 0.993 and a linear analytical curve equation of $\mathrm{y}=203.404 \mathrm{x}+106.733$. After images decomposition it was observed that channel $\mathrm{B}$ presented the highest values when compared with $\mathrm{R}$ and $\mathrm{G}$, being the most sensitive channel among the 8 tested.

Figure 2a shows the analytical curve for color channel $\mathrm{B}$, and Figure $2 \mathrm{~b}$ show the colors of the standard solutions used in the analytical curve. An attractive feature of PhotoMetrix is that the analytical curves are obtained on the app (Figure 2a). In addition, the concentrations predicted by the colors can be also observed in the app. The pink/violet coloration, shown in Figure $2 b$, is derived from the colorimetric reaction between $\mathrm{Cr}(\mathrm{VI})$ and the chromogenic reagent DPC. The overall reaction between $\mathrm{Cr}(\mathrm{VI})$ and $\mathrm{DPC}$ is presented in Equation 1.

$$
\begin{aligned}
& 2 \mathrm{CrO}_{4}{ }^{2-}+3 \mathrm{H}_{4} \mathrm{~L}+8 \mathrm{H}^{+} \\
& \mathrm{Cr}^{3+}+\mathrm{H}_{2} \mathrm{~L}+8 \mathrm{H}_{2} \mathrm{O}
\end{aligned}
$$

The DPC $\left(\mathrm{H}_{4} \mathrm{~L}\right)$ is oxidized to diphenylcarbazone $\left(\mathrm{H}_{2} \mathrm{~L}\right)$, whereas $\mathrm{Cr}(\mathrm{VI})$ is reduced to $\mathrm{Cr}$ (III) forming the pink/violet color complex $\quad \mathrm{Cr}(\mathrm{III}) \quad$ - diphenylcarbazone $\left[\mathrm{Cr}(\mathrm{IIII})(\mathrm{HL})_{2}\right]^{+}$, the reaction occurs in acid medium and the complex has maximum absorbance at 540 $\mathrm{nm}$. 


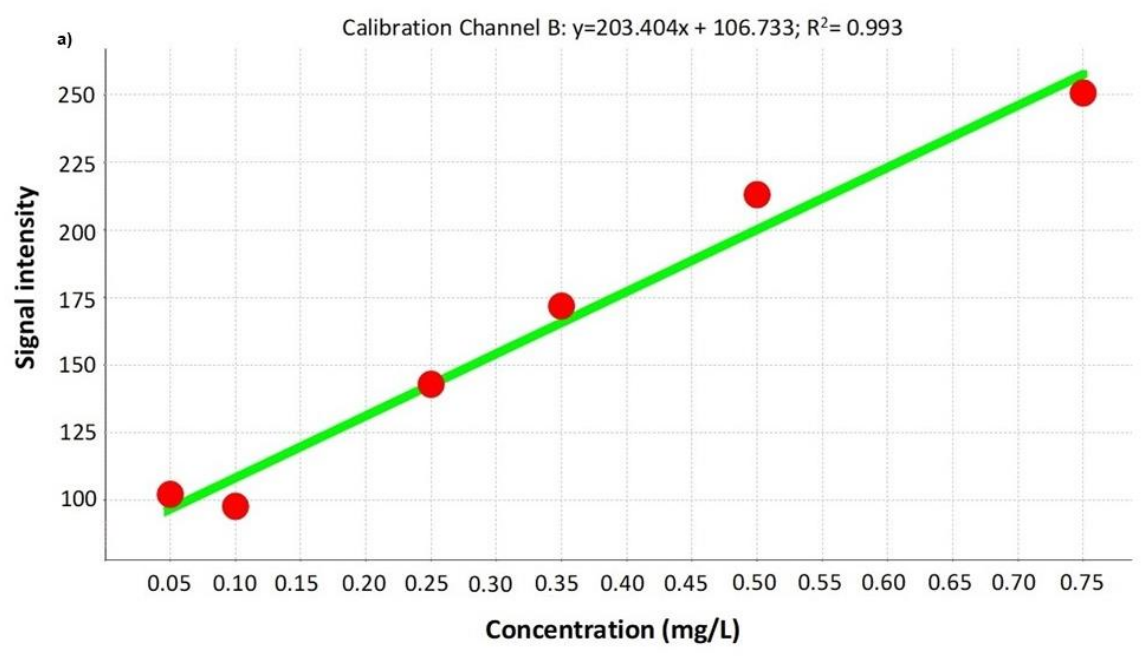

b)

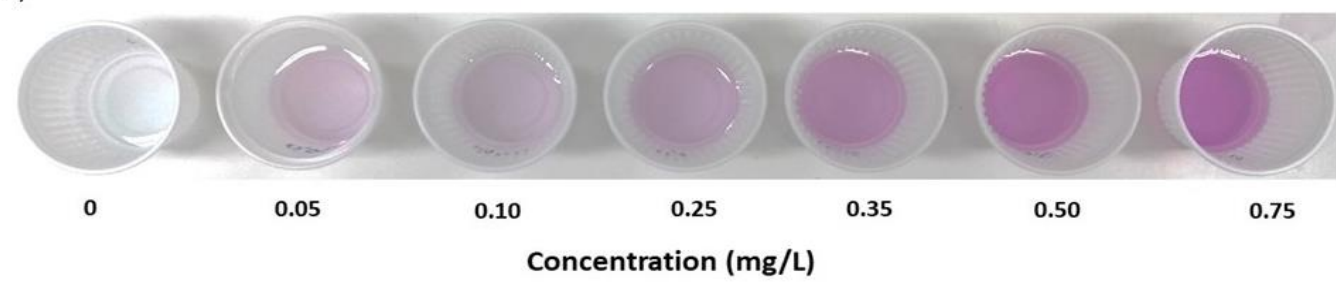

Figure 2. a) Analytical curve in the range of $0.05-0.75 \mathrm{mg} \mathrm{L}^{-1}$; b) colors related with standards used in analytical curve.

\subsection{Validation and application}

The limits of detection (LOD) and quantification (LOQ) were calculated according International Union of Pure and Applied Chemistry (IUPAC) recommendations ${ }^{13}$. The LOD and LOQ of method proposed were 0.6 and $2 \mathrm{mg} \mathrm{kg}^{-1}$, respectively. These values were obtained after multiplying the LOD and LOQ values from the analytical curve by the dilution factor $(20,000$ fold). The precision estimated as the relative standard deviation (\%RSD, $\mathrm{n}=7$ ) was determined from seven measurements for the extractions performed on a sample of leather with a concentration of $14 \mathrm{mg} \mathrm{L}^{-1}$ of $\mathrm{Cr}(\mathrm{VI})$, and the RSD obtained was $7.5 \%$. To evaluate the accuracy of the proposed method, addition and recovery experiments were employed. Samples were spiked with standard solutions of $50 \mathrm{mg} \mathrm{L}^{-1} \mathrm{Cr}$ (III) and $50 \mathrm{mg} \mathrm{L}^{-1} \mathrm{Cr}(\mathrm{VI})$ before alkaline extraction, and the obtained recoveries were in the range $98-124 \%$. The results are shown in Table 2. No species conversion (oxidation) from III to VI was observed.
In addition, the results obtained through the method developed in this research were compared to those obtained by a reference method using UVVis, and the results of the concentrations of total $\mathrm{Cr}, \mathrm{Cr}(\mathrm{III})$ and $\mathrm{Cr}(\mathrm{VI})$ are presented in Table 3.

A statistical evaluation using two-sample t-test showed that there is no difference between the $\mathrm{Cr}(\mathrm{VI})$ values obtained with the use of the proposed and the reference method at the $95 \%$ confidence level. The concentrations of $\mathrm{Cr}(\mathrm{VI})$ determined in the bovine leather samples tanned with $\mathrm{Cr}$ salts showed, as expected, the highest values, varying from $1420-2100 \mathrm{mg} \mathrm{kg}^{-1}$. On the other hand, the ovine leather samples tanned with vegetable tannins presented $\mathrm{Cr}(\mathrm{VI})$ concentration lower than the LOQ of the proposed method. The samples analyzed show values of $\mathrm{Cr}(\mathrm{VI})$ concentration above the limits set by the European Union that established a maximum concentration of $\mathrm{Cr}(\mathrm{VI})$ of $3 \mathrm{mg} \mathrm{kg}^{114}$. The use of vegetable tannins shows this treatment is in accordance with principles of green chemistry. 
Table 2. Samples spiked with standard solutions of $\mathrm{Cr}(\mathrm{III})$ and $\mathrm{Cr}(\mathrm{VI})$ before alkaline extraction and \% trueness of $\mathrm{Cr}(\mathrm{VI})$ (mean \pm standard deviation; $\mathrm{n}=3$ ).

\begin{tabular}{cccc}
\hline $\begin{array}{c}\text { Leather } \\
\text { samples }\end{array}$ & $\begin{array}{c}\text { Simultaneous addition } \\
\left(\mathbf{m g ~ L}^{-1}\right) \text { of } \mathbf{C r}(\mathbf{I I I}) \text { and } \\
\mathbf{C r}(\mathbf{V I})\end{array}$ & $\begin{array}{c}\text { Found }\left(\mathbf{m g ~ L}^{-1}\right) \mathbf{C r} \\
(\mathbf{V I})\end{array}$ & \% recovery (CrVI) \\
\hline $\begin{array}{c}\text { Sample } 1 \\
\text { (bovine) }\end{array}$ & 0 & $18 \pm 1$ & - \\
\hline $\begin{array}{c}\text { Sample 2 } \\
\text { (bovine) }\end{array}$ & 50 & $76 \pm 5$ & 116 \\
\hline $\begin{array}{c}\text { Sample 3 } \\
\text { (bovine) }\end{array}$ & 0 & $21 \pm 1$ & - \\
\hline $\begin{array}{c}\text { Sample 4 } \\
\text { (bovine) }\end{array}$ & 50 & $76 \pm 4$ & 110 \\
\hline $\begin{array}{c}\text { Sample 5 } \\
\text { (ovine) }\end{array}$ & 0 & $14 \pm 1$ & - \\
\hline Sample 6 & 50 & $67 \pm 2$ & 106 \\
(ovine) & 0 & $19 \pm 1$ & - \\
\hline $\begin{array}{c}\text { Sample 7 } \\
\text { (ovine) }\end{array}$ & 0 & $69 \pm 3$ & - \\
\hline & 50 & - & 114 \\
\hline
\end{tabular}

Table 3. Determination of total Cr by ICP OES and Cr(VI) in leather samples by UV-Vis and proposed method.

\begin{tabular}{|c|c|c|c|c|}
\hline \multirow{3}{*}{$\begin{array}{l}\text { Leather } \\
\text { samples }\end{array}$} & \multicolumn{4}{|c|}{ Concentration $\left(\mathrm{mg} \mathrm{kg}^{-1}\right)$} \\
\hline & \multirow{2}{*}{$\begin{array}{c}\text { Total Cr } \\
\text { Reference } \\
\text { method } \\
\text { (ICP OES) }\end{array}$} & \multirow{2}{*}{$\begin{array}{c}\mathrm{Cr}(\mathrm{III}) \\
\text { Total Cr - } \\
\text { Cr VI }\end{array}$} & \multicolumn{2}{|c|}{$\operatorname{Cr}(\mathrm{VI})$} \\
\hline & & & $\begin{array}{l}\text { Proposed method } \\
\text { (digital image) }\end{array}$ & $\begin{array}{c}\text { Reference method } \\
\text { (UV-Vis) }\end{array}$ \\
\hline $\begin{array}{l}\text { Sample } 1 \\
\text { (bovine) }\end{array}$ & $16419 \pm 435$ & $14609 \pm 545$ & $1810 \pm 113$ & $1728 \pm 105$ \\
\hline $\begin{array}{l}\text { Sample } 2 \\
\text { (bovine) }\end{array}$ & $16917 \pm 261$ & $14817 \pm 345$ & $2100 \pm 85$ & $2006 \pm 87$ \\
\hline $\begin{array}{l}\text { Sample } 3 \\
\text { (bovine) }\end{array}$ & $15091 \pm 471$ & $13671 \pm 528$ & $1420 \pm 57$ & $1337 \pm 112$ \\
\hline $\begin{array}{c}\text { Sample } 4 \\
\text { (bovine) }\end{array}$ & $20445 \pm 688$ & $18535 \pm 815$ & $1910 \pm 127$ & $1795 \pm 96$ \\
\hline $\begin{array}{l}\text { Sample } 5 \\
\text { (ovine) }\end{array}$ & $19 \pm 2$ & - & $<\mathrm{LOQ}$ & $<\mathrm{LOQ}$ \\
\hline $\begin{array}{l}\text { Sample } 6 \\
\text { (ovine) }\end{array}$ & $25 \pm 2$ & - & $<\mathrm{LOQ}$ & $<\mathrm{LOQ}$ \\
\hline $\begin{array}{l}\text { Sample } 7 \\
\text { (ovine) }\end{array}$ & $10 \pm 3$ & - & $<\mathrm{LOQ}$ & $<\mathrm{LOQ}$ \\
\hline
\end{tabular}

The $\operatorname{Cr}(\mathrm{VI})$ values found are high and worrisome, since studies with sensitized individuals revealed that at a level of $5 \mathrm{mg} \mathrm{kg}^{-1}$ of $\mathrm{Cr}$, half of the people evaluated presented allergic skin reactions ${ }^{15}$. Normally, leather tanning involves the use of $\mathrm{Cr}(\mathrm{III})$. However, there have been many reports that $\mathrm{Cr}(\mathrm{VI})$ has been abnormally detected in some leather samples, but this has been widely debated $^{16}$. In time, the chemicals used in production and other environmental factors, such as heat and light, may cause changes and deformations in leather products, e.g., oxidation of $\mathrm{Cr}(\mathrm{III})$ to $\mathrm{Cr}(\mathrm{VI})$, a decrease in shrinkage temperature, fading or yellowing color, a loss of 
physical resistance, and odor problems due to oxidation of fat liquors or formaldehyde release. These deformations generally occur due to oxidant groups - free radicals, which arise depending on these factors.

\subsection{Note to faculty}

In technological terms, our society has changed substantially in the last decades. Not only did computers become ubiquitously part of school space or homes, but mobile phone also invaded the hands of students and teachers. It is well known in the literature that teacher can use tools accessible to students, aiming at a contextualized teaching. Contextual teaching draws the attention of students, since the reality of their day can be lived in the classroom. Nowadays every student has a mobile phone, and this may be an opportunity for the teacher to introduce chemical concepts from colorimetric experiments, in which students use their mobile phone as an instrument of analysis. This type of activity addresses the concept of contextualized teaching.

In the experiments proposed in this study using a mobile phone, we highlight the importance of the used app (PhotoMetrix), which facilitates the development of the class and student learning. In this sense, the use of these tools can be a strategy used by teachers in experimental classes, with the purpose of contributing to the intellectual development and awakening the scientific interest of these students who could become future researchers.

From this experiment, several chemical concepts can be approached in the classroom and are listed below:

- Quantitative analysis;

- Chemical speciation;

- Environmental chemistry;

- Solution preparation and construction of a calibration curve;

- Sample preparation;

- Planning and executing experiments through the use of appropriate chemical literature and electronic resources;

- The use of statistical tools can also be approached from analyzing data statistically, assessing the reliability of experimental results, and discussing the sources of systematic and random error in experiments;
- Validation of the analytical procedure.

\subsection{Students opinion about the use of Photometrix in experimental class}

Currently, many students have a mobile phone and are willing to install a free app, such as the PhotoMetrix. This approach shows that it is possible to use materials in the daily lives of students in the classroom. The utility of this method lies not only in its efficacy for determining $\mathrm{Cr}(\mathrm{VI})$ concentration via the measurement of a color change but also in its robustness in a range of factors, including lighting conditions and picture quality, which can vary dramatically from one classroom to another. In addition, the samples used in this experiment can be easily obtained and are present in the daily lives of the students. The students found the experiment interesting, mainly because they could compare the results obtained with PhotoMetrix with those obtained with an equipment, such as a UV-Vis as was performed in this study.

The students' evaluation from the experimental procedure was very positive, mainly due to the fact they used their own mobile phones in data acquisition and treatment. This experiment was performed in a course named "Qualitative and Quantitative Analysis in Chemistry" and at the end of at least 4 experimental classes performed in different semesters, 20 students answered some questions about the use of Photometrix in the experimental classes. Figure $2 \mathrm{~S}$ summarizes the students' opinions.

\section{Conclusions}

The proposed method for $\mathrm{Cr}(\mathrm{VI})$ speciation and determination in leather samples using digital images from mobile phones was shown to be very efficient. The results obtained with the proposed procedure demonstrated good accuracy with values obtained from a reference method by UV-Vis. This method can be used in routine analyses for determination of $\mathrm{Cr}(\mathrm{VI})$ in leather samples. In addition, the method can be used in experimental analytical chemistry courses. The students can be motivated by learning that their mobile phones can be used as effective analytical devices. Another benefit of this approach is that students can see with their eyes what they are measuring and understand. 


\section{Acknowledgments}

This study was supported by the São Paulo Research Foundation (FAPESP, 2016/01513-0), the Conselho Nacional de Desenvolvimento Científico e Tecnológico (CNPq, 401074/2014-5 and 305637/2015-0), and Embrapa. This study was financed in part by the Coordenação de Aperfeiçoamento de Pessoal de Nível Superior Brasil (CAPES) - Finance Code 001.

\section{References}

[1] Sussulini, A., Arruda, M. A. Z., Determinação de cromo (VI) por espectrometria de absorção atômica com chama após a extração e préconcentração no ponto, Eclet. Quím. J. 31 (2006) 73-80. $\quad$ https://doi.org/10.1590/S010046702006000100009

[2] Capitán-Vallvey, L. F., López-Ruiz, N., Martínez-Olmos, A., Erenas, M. M., Palma, A. J., Recent developments in computer vision-based analytical chemistry: A tutorial review. Anal. Chim. Acta, $899 \quad$ (2015) 23-56. https://doi.org/10.1016/j.aca.2015.10.009.

[3] Santos, P. M., Pereira-Filho, E. R., Digital image analysis - an alternative tool for monitoring milk authenticity, Anal. Methods. 5 (2013) 36693674. https://doi.org/10.1039/C3AY40561C.

[4] Colzani, H., Rodrigues, Q. E. A. G., Fogaça, C., Gelinski, L. N., Pereira-Filho, E. R., Borges, E. M., Determinação de fosfato em refrigerantes utilizando um scanner de mesa e análise automatizada de dados: um exemplo didático para ensino de química, Quim. Nova. 40 (2017) 833839. 4042.20170035 .

[5] Montangero, M., Determining the Amount of Copper (II) Ions in a Solution Using a Smartphone, J. Chem. Educ. 92 (2015) 1759-1762. https://doi.org/10.1021/acs.jchemed.5b00167.

[6] Moraes, E. P., Confessor, M. R., Gasparotto, L. H. S., Low-Cost Method for Quantifying Sodium in Coconut Water and Seawater for the Undergraduate Analytical Chemistry Laboratory: Flame Test, a Mobile Phone Camera, and Image
Processing, J. Chem. Educ. 92 (2015) 1696-1699. https://doi.org/10.1021/ed400797k.

[7] Gomes, M. S., Trevisan, L. C., Nóbrega, J. A., Kamogawa, M. Y., Uso de scanner em espectrofotometria de absorção molecular: aplicação em experimento didático enfocando a determinação de ácido ascórbico, Quim. Nova. 31 (2008) 1577-1581. https://doi.org/10.1590/S010040422008000600050 .

[8] Grasel, F. S., Ferrão, M. F., Helfer, G. A., Costa, A. B., Principal Component Analysis of Commercial Tannin Extracts Using Digital Images on Mobile Devices, J. Braz. Chem. Soc. 27 (2016) 2372-2377. https://doi.org/10.5935/01035053.20160135 .

[9] Helfer, G. A., Magnus, V. S., Bock, F. A., Teichmann, A., Ferrão, M. F., Da Costa, A. B., PhotoMetrix: An Application for Univariate Calibration and Principal Components Analysis Using Colorimetry on Mobile Devices, J. Braz. Chem. Soc. $28 \quad$ (2017) 328-335. https://doi.org/10.5935/0103-5053.20160182.

[10] Dixit, S., Yadav, A., Dwivedy, P. D., Das, M., Toxic hazards of leather industry and technologies to combat threat: a review, J. Clean. Prod. 87 (2015) 39-49. https://doi.org/10.1016/j.jclepro.2014.10.017.

[11] Neiva, A. N., Pereira-Filho, E. R., Evaluation of the Chemical Composition of Synthetic Leather Using Spectroscopy Techniques. Appl. Spectrosc. $72 \quad$ (2018) 921-932. https://doi.org/10.1177/0003702818764922.

[12] Oliveira, L. F., Canevari, N. T., Guerra, M. B. B., Pereira, F. M. V., Schaefer, C. E. G. R., PereiraFilho, E. R., Proposition of a simple method for chromium (VI) determination in soils from remote places applying digital images: A case study from Brazilian Antarctic Station, Microchem J. 109 (2013)

$165-169$. https://doi.org/10.1016/j.microc.2012.03.007.

[13] Belter, M., Sajnog, A., Barałkiewicz, D., Over a century of detection and quantification capabilities in analytical chemistry-historical overview and trends. Talanta, 129 (2014) 606-616. https://doi.org/10.1016/j.talanta.2014.05.018. 
[14] ISO 17075. (2007). Leather - Chemical Tests - Determination of Chromium (VI) Content. International Organization for Standardization.

[15] BFR (Bundesinstitut fur Risikobewertung). Chromium (VI) in leather clothing and shoes problematic for allergy sufferers. (2007) <http://www.bfr.bund.de/cd/9575>. Accessed 10 December 2017.
[16] Neiva, A. M., Sperança, M. A., Costa, V. C., Jacinto, M. A. C., Pereira-Filho, E. R., Determination of toxic metals in leather by wavelength dispersive X-ray fluorescence (WDXRF) and inductively coupled plasma optical emission spectrometry (ICP OES) with emphasis on chromium. Environ. Monit. Assess. 190, (2018) 618-631. https://doi.org/10.1007/s10661-0186990-y. 


\section{Supplementary Material}

\section{Chromium speciation in leather samples: an experiment using digital images, mobile phones and environmental concepts}

a)

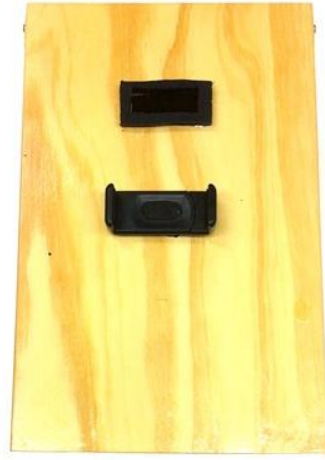

b)

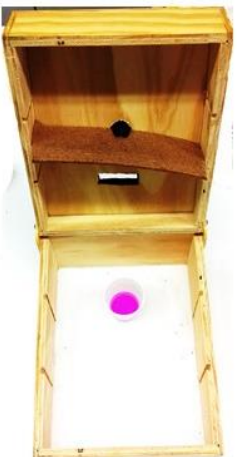

c)

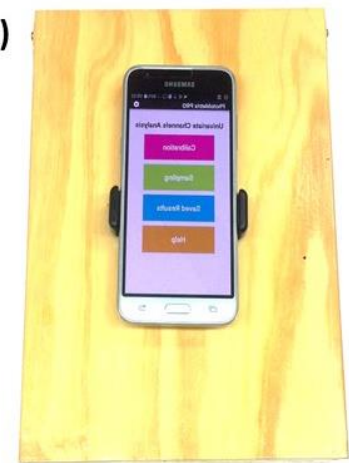

Figure 1S. a) Wooden box with a holder to attach the phone and a hole for the phone camera; b) profile of the interior of the wooden box with the sample; c) wooden box with the phone in the holder. 


\section{Question}

1 - What is your opinion about the operation and results interpretation obtained from Photometrix?

2-Did you have an idea about this type of mobile phone application before this experimental class?

3 - Could you use Photometrix in your other classes?
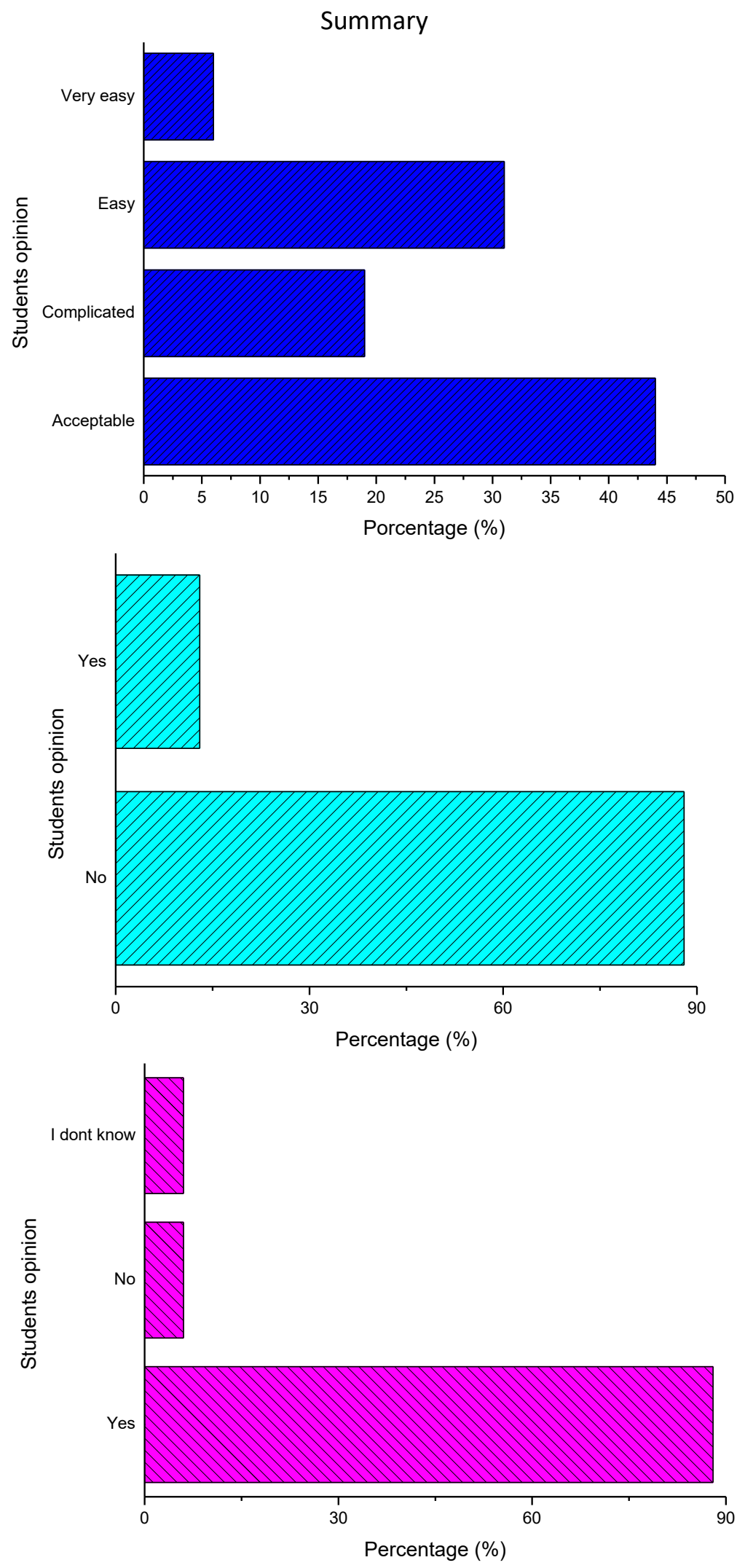
4-Would you like Photometrix to be used in other experimental classes?

5 - What is your opinion about the use of Photometrix and instrumental techniques?
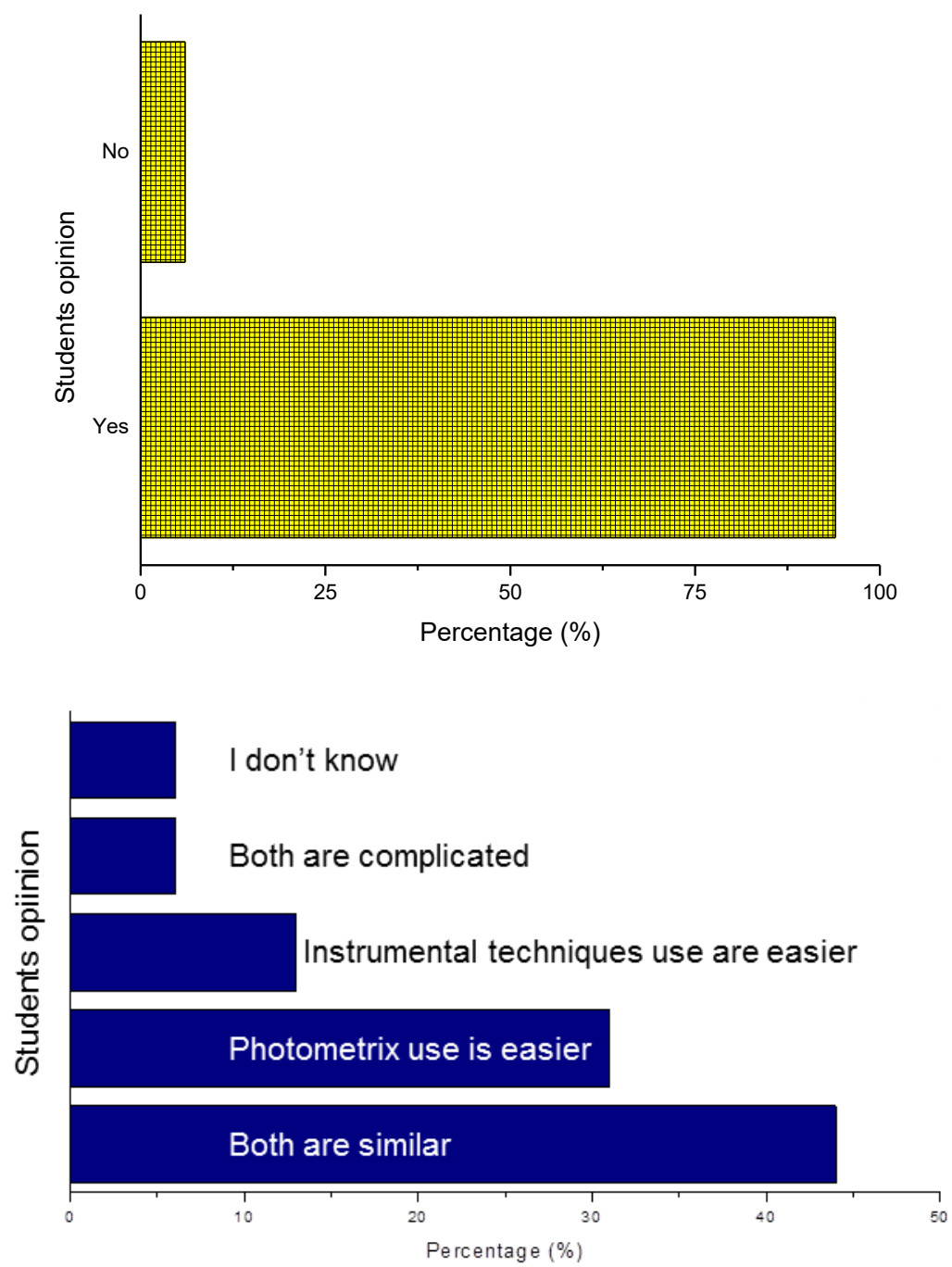

Figure 2S. Students' opinions about the use of Photometrix in the experimental class. 
Table S1. Operational parameters for ICP OES determinations.

\begin{tabular}{lc}
\hline Instrument parameter & $\begin{array}{c}\text { Operational } \\
\text { conditions }\end{array}$ \\
\hline Radio frequency applied power $(\mathrm{kW})$ & 1.15 \\
Integration time for low emission line $(\mathrm{s})$ & 15 \\
Integration time for high emission line $(\mathrm{s})$ & 5 \\
Sample introduction flow rate $\left(\mathrm{mL} \mathrm{min}^{-1}\right)$ & 2.1 \\
Pump stabilization time $(\mathrm{s})$ & 5 \\
Argon auxiliary flow rate $\left(\mathrm{L} \mathrm{min}^{-1}\right)$ & 0.5 \\
Argon plasma flow rate $(\mathrm{L} \mathrm{min})$ & 12 \\
Argon nebulizer flow rate $\left(\mathrm{L} \mathrm{min}^{-1}\right)$ & 0.7 \\
Replicates & 3 \\
Element and wavelength $(\mathrm{nm})$; View modes: & $\mathrm{Cr} \mathrm{I}(283.5)$ \\
axial and radial. & \\
\hline
\end{tabular}


